\title{
Sural nerve injury associated with neglected tendo Achilles ruptures
}

\author{
M D A Fletcher, P J Warren
}

\begin{abstract}
Two patients are described with delayed presentation of a ruptured tendo Achilles, each exhibiting signs of sural nerve dysfunction. Recovery occurred in each case after operative repair.

(Br F Sports Med 2001;35:131-132)
\end{abstract}

Keywords: sural nerve injury; tendo Achilles rupture; Bosworth repair

Rupture of the tendo Achilles is a commonly seen injury, with an incidence of between 2 and 12 cases per 100000 people per year. ${ }^{12}$ Whereas intraoperative injury to the sural nerve is a well recognised but relatively uncommon complication, we believe injury to the sural nerve occurring as a direct consequence of tendon rupture to have been previously unreported. We describe two cases in which injury to the sural nerve was identified before operative repair of a ruptured tendo Achilles presenting late.

\section{Case report 1}

A 41 year old man, with no previous history of injury to the right lower leg, sustained a subcutaneous rupture of his right tendo Achilles while sprinting. Initially he opted to be treated non-operatively by progressive serial casting from equinus to plantigrade over an eight week period. On review at 12 weeks, he complained of persisting pain at the site of injury and the inability to plantarflex his foot from neutral. Clinical examination showed a 5 $\mathrm{cm}$ gap in the tendo Achilles and also an objective loss of sensation in the distribution of the sural nerve in the same foot.

At operation, a Bosworth turn down repair ${ }^{3}$ of the tendo Achilles was performed through a posterior longitudinal midline incision because it was impossible to approximate the free ends of the tendon without excessive tension. In view of the sural nerve signs before the operation, the sural nerve was examined at the time of surgery and, although found to be intact, was noted to be stretched adjacent to the ruptured segment of tendon. The nerve was freed by gentle dissection; it was apparent that no dense scar tissue related to it was present.

An above knee cast in equinus was applied at the time of surgery. This was changed to a below knee equinus cast at two weeks. Over the following eight weeks, a series of casts were applied to bring the foot from equinus to plantigrade. The leg was immobilised for a total of 10 weeks.

After the operation, there was an objective improvement in sensation in the distribution of the sural nerve, and it had returned to normal three months after surgery. The patient regained active plantarflexion of the ankle. No complications occurred as a result of surgery.

\section{Case report 2}

A 53 year old man presented five weeks after rupturing his tendo Achilles during a game of badminton. Initially he sought treatment from an osteopath. He presented to our department after his symptoms failed to resolve. Clinical examination at this time showed a positive Simmonds sign and altered sensation within the distribution of the sural nerve.

Delayed primary repair of the tendo Achilles rupture was performed through a posterolateral approach, with subsequent immobilisation in a series of casts, varying from equinus to plantigrade over the course of eight weeks. At cast removal, it was noted that sensation within the distribution of the sural nerve had recovered, and the integrity of the repair was confirmed.

\section{Discussion}

Cadaver studies have shown considerable variation in the course of the sural nerve between individuals. ${ }^{45}$ This is of importance because the nerve crosses the lateral border of the tendo Achilles at a variable position along the tendon, ${ }^{5}$ and therefore may be at risk of intraoperative injury. Such injuries are most common after percutaneous repair, particularly if sutures are placed laterally, with a reported incidence of between 7 and $60 \% .^{6}{ }^{78}$ Non-surgical injury to the sural nerve has been observed following entrapment in scar tissue as a result of haematoma, ${ }^{9}$ but no dense scar tissue was evident on exploration of the nerve in either of these cases. The mechanism of nerve dysfunction in these cases probably results from stretching of the nerve when the foot was inadvertently dorsiflexed; the absence of an intact tendo Achilles acting as a check rein allowed the nerve to be stretched beyond its normal physiological limits.

Older ruptured Achilles tendons often present with profound impairment of normal day to day activities, ${ }^{10}$ and under these circumstances it is relatively easy to overlook concomitant pathology. We feel that the importance of these cases lies in drawing attention to the possibility of associated sural nerve injury and, also, it reinforces the importance of careful clinical examination in the identification of any such associated injuries. In the light of increasing litigation for operative complications, structures at risk should be considered before surgery and their function noted, as they may be dysfunctional before surgical intervention. 
1 Leppilahti J, Puranen J, Orava S. Incidence of Achilles tendon rupture. Acta Orthop Scand 1996;67:277-9.

Maffulli N, Waterston SW, Squair J, et al. Changing incidence of Achilles tendon rupture in Scotland: a 15-year study. Clin F Sport Med 1999;9:157-60.

3 Bosworth DM. Repair of defects in the tendo Achilles. $f$ Bone foint Surg [Am] 1956;38:111-14.

4 Lawrence SJ, Botte MJ. The sural nerve in the foot and ankle: an anatomical study with clinical and surgical implications. Foot Ankle Int 1994;15:490-4.

5 Webb J, Moorjani N, Radford M. Anatomy of the sural nerve and its relation to the Achilles tendon. Foot Ankle Int 2000;21:475-7.
6 Fitzgibbons RE, Hefferon J, Hill J. Percutaneous Achilles tendon repair. Am f Sports Medicine 1993;21:724-27.

7 Hockenbury RT, Johns JC. A biomechanical in vitro comparison of open versus percutaneous repair of tendon Achilles. Foot Ankle 1990;11:67-72.

8 Klein W, Lang DM, Saleh M. The use of the Ma-Griffith technique for percutaneous repair of fresh ruptured tendo Achilles. Chir Organi Mov 1991;76:223-8.

9 Bryan BM 3rd, Lutz GE, O’Brien SJ. Sural nerve ntrapment after injury to the gastrocnemius. A case report. Arch Phys Med Rehabil 1999;80:604-6.

10 Maffulli N. Rupture of the Achilles tendon. F Bone foint Surg [Am] 1999;81:1019-36.

\section{Take home message}

Neglected tendo Achilles ruptures often present with significant functional impairment, which may mask an associated sural nerve injury. The sural nerve is at risk of injury during surgical repair, therefore examination is advised to document its preoperative function.

Please note that the editorial office of British fournal of Sports Medicine has moved. Please send all future communications to: Dr Paul McCrory, British fournal of Sports Medicine, Centre for Sports Medicine Research \& Education, School of Physiotherapy Level 1, 200 Berkeley Street, Parkville, Victoria 3052, Australia. Tel: +61 38344 4118; Fax: +61 38344 3771; Email: jemcki@unimelb.edu.au 